\title{
Turismo em Nova Petrópolis: perspectivas de desenvolvimento do turismo cultural
}

\author{
Rodrigo José dos Santos* \\ Vania Beatriz Merlotti Heredia**
}

\begin{abstract}
Resumo
O presente estudo traz para a discussão possibilidades de desenvolvimento do turismo cultural no município de Nova Petrópolis. Tem por objetivo reunir e sistematizar informações sobre a vinda dos imigrantes alemães para o Rio Grande do Sul em 1824, e por consequência, a chegada em Nova Petrópolis no ano de 1858. A proposta do estudo inclui a criação do cooperativismo, numa das comunidades de Nova Petrópolis, Linha Imperial, considerada o berço do cooperativismo na América Latina. A comunidade da Linha Imperial possui uma forte cultura na área do cooperativismo e seu estudo permite entender ações que foram desencadeadas a partir da chegada dos alemães nessa localidade que hoje integra a região turística das Hortênsias. $O$ estudo foi dividido em três momentos sendo o primeiro uma contextualização da chegada dos imigrantes na região; o segundo o desenvolvimento do cooperativismo em Nova Petrópolis e o terceiro a vinculação da comunidade e o turismo cultural. A pesquisa realizada é de natureza bibliográfica e contou com documentos e resultados de outras pesquisas acerca da imigração alemã no Rio Grande do Sul. Uma das primeiras comunidades fundadas foi Linha Imperial, onde se verifica a organização da localidade por meio de princípios e valores culturais trazidos da terra de origem. Constata-se que o estudo dessa comunidade pode contribuir para o desenvolvimento do turismo no município de Nova Petrópolis.
\end{abstract}

Palavras-chave: Turismo cultural. Imigração alemã. Patrimônio cultural. Linha Imperial. Cooperativismo

\section{Tourism in Nova Petrópolis: perspectives for the development of cultural tourism}

\begin{abstract}
This study draws attention to possibilities for developing cultural tourism in Nova Petrópolis. It aims to collect and organize information about the arrival of German immigrants in Rio Grande do Sul in 1824, and, consequently, their arrival in Nova Petrópolis in 1858. This study's proposal includes the creation of cooperativism, which took place in one of the communities in Nova Petrópolis, Linha Imperial, considered to be the birthplace of cooperativism in Latin America. The community Linha Imperial has a strong culture of cooperativism, therefore, studying about it enables the understanding of actions that were instigated as of the Germans' arrival in this location that today is part of the Hortênsias touristic region. The study was divided into three moments, the first being a contextualization of the immigrants' arrival in the region: the second, the development of cooperativism in Nova Petrópolis and the third, the link between the community and cultural tourism. The research is of bibliographical nature and relied on documents and results of other studies on the topic of German immigration to Rio Grande do Sul. One of the first founded communities was Linha Imperial, where it is possible to verify its own organization based on cultural principles and values brought from the homeland. It is determined that the study of this community can contribute to the development of tourism in Nova Petrópolis.
\end{abstract}

Keywords: Cultural tourism. German immigration. Cultural heritage. Linha Imperial. Cooperativism.

\section{Introdução}

A motivação para estudar a história de Nova Petrópolis nasce através de inquietações como morador do município e da importância que seus habitantes atribuem a sua formação

\footnotetext{
* Mestrando do Programa de Pós-Graduação em Turismo e Hospitalidade (PPGTURH) da Universidade de Caxias do Sul (UCS). E-mail: rodrigosantosnp@hotmail.com

** Doutorado em História das Américas (Universidade de Gênova) e Pós-Doutorado em História Econômica (Universidade de Padova). Professora do Programa de Pós-Graduação em Turismo e Hospitalidade (PPGTURH) da Universidade de Caxias do Sul (UCS). E-mail: vheredia@zaz.com.br
} 
histórica e seus desdobramentos. O estudo do município de Nova Petrópolis abre um leque de possibilidades ao olhar para a história de comunidades que dele fazem parte e vislumbrar seu potencial turístico e a necessidade de preservação de seu patrimônio. O presente estudo tem por objetivo trazer para a discussão essa história e sua relação com o cooperativismo, o que oportuniza a visualização de uma proposta de turismo cultural, que pode ser fomentada pela gestão pública municipal e por iniciativas privadas, com vistas a promover um desenvolvimento sustentável do local e preservação de seu patrimônio cultural.

Drechsler ${ }^{1}$ destaca a importância da preservação e manutenção da história e memória da comunidade, como elemento identitário daqueles que fazem parte do lugar. Diz que:

$\mathrm{Na}$ alma de cada filho desta terra encontra-se gravada a imagem venerada de uma avó ou de um avô, contando a sua versão das "histórias de antigamente". E as novas gerações cresceram, arraigadas ao torrão natal, num sentimento profundo e místico que atravessa o espaço e o tempo. Coube-nos a honrosa tarefa de resgatar a memória dos antepassados, fortalecendo assim, a auto-imagem das novas gerações (DEPPE, 1988, p. 13).

Esse depoimento mostra a força da cultura local no município de Nova Petrópolis, que é homogênea e preservada em toda essa região. Trazer para conhecimento público as histórias existentes na localidade onde nasce o cooperativismo demonstra alternativas de desenvolvimento do turismo cultural, através de estudos da história local.

Nesse contexto, as possibilidades de turismo que são possíveis como propostas de desenvolvimento para o município, identifica-se que o turismo cultural seria uma opção adequada visto que "[...] compreende as atividades turísticas relacionadas à vivência do conjunto de elementos significativos do patrimônio histórico e cultural e dos eventos culturais, valorizando e promovendo os bens materiais e imateriais da cultura" (MINISTÉRIO DO TURISMO, 2010, p.15).

Por meio do turismo cultural é possível propor a manutenção de patrimônios, como fator de preservação, o que possibilita o conhecimento e a bagagem cultural para os turistas que interagem com novas culturas e informações, fatos históricos e locais importantes, aumentando a experiência e a vivência cultural.

\section{Nova Petrópolis e sua história}

Nova Petrópolis está localizada no nordeste do Rio Grande do Sul, na Região das

\footnotetext{
${ }^{1}$ Sigfried Drechsler, ex-prefeito de Nova Petrópolis, em seu relato no livro "Contribuição para a história de Nova Petrópolis" mostra a força e a importância da memória da comunidade para manter a identidade.
} 
Hortênsias que é uma das regiões turísticas mais importantes do Brasil, juntamente com os municípios de Gramado, Canela, São Francisco de Paula, Picada Café e Caxias do Sul, conforme o Mapa do Turismo do Governo Federal de 2017 - 2019 (MINISTÉRIO DO TURISMO, 2020).

Situada estrategicamente na Serra Gaúcha, ao lado da Região Uva e Vinho, referência turística onde se encontram Bento Gonçalves, Garibaldi, Carlos Barbosa e outras importantes cidades colonizadas pelos imigrantes italianos. A capital gaúcha Porto Alegre fica a 90 quilômetros, juntamente com o Aeroporto Internacional Salgado Filho e distante 35 quilômetros do Aeroporto Regional de Caxias do Sul, estando nas principais rotas de acesso turístico do Rio Grande do Sul (ACINP, s./d.).

Nova Petrópolis é colonizada por imigrantes alemães que deixaram a sua pátria devido às dificuldades que enfrentaram no começo do século XIX. O cenário das sociedades de onde partiram os emigrantes refletem as motivações pelas quais muitos grupos deixaram seus países de origem. A Europa passava por um momento muito difícil, "a Alemanha saíra das guerras napoleônicas, que causaram uma devastação fácil de imaginar: lavouras destruídas seguidamente, moradias em chamas, mortes, dizimação da juventude masculina, a soldadesca deixando seus rastros junto ao elemento feminino" (CAPEF, 2011)2.

Após as guerras napoleônicas, a população alemã passou por grandes dificuldades, os conflitos trouxeram avanços tecnológicos e a industrialização na Europa, causou a troca da mão de obra pelas máquinas, deixando levas de trabalhadores desempregados. Com todas as dificuldades algumas regiões facilitaram a imigração para diminuir a pressão demográfica e, também, se livraram de marginais, indigentes e incapazes, enviando-os para o Brasil (BRAUN, 2017).

Além das longas guerras napoleônicas, os anos de 1816 e 1817 foram de pobreza, pestes nas lavouras, epidemias, fome e frio, tudo por influência da erupção do vulcão do Monte Tambora no dia 10 de abril de 1815, em Sumbawa na Indonésia. Ao longo do ano seguinte uma densa nuvem de cinzas pairou sobre os céus, o que gerou chuvas e geadas devastadoras. Ainda se somava os trabalhos pouco remunerados e insalubres que eram submetidos para o sustento das famílias. Estas circunstâncias tornou a população mais pobre, sendo um dos fatores que fizerem os alemães emigrar para o Brasil (BRAUN, 2017).

Arend e Witt (2005), apresentam o lado brasileiro no interesse de trazer o europeu para a América do Sul. O governo imperial necessitava povoar a região em estudo, principalmente por

\footnotetext{
${ }^{2}$ CAPEF- Centro de Apoio a Pesquisas e Encontros Familiares). Fonte: http://www.genealogiacapef.com.br/index.php/de/fatos-historicos/133-imigracao-alema
} 
questões militares devido aos conflitos externos na região do Rio da Prata. As distâncias para proteção das fronteiras eram grandes, estando a mais 1.500 quilômetros de Laguna e 2.500 quilômetros de São Paulo. As tentativas anteriores de povoamento com a concessão de sesmarias ou com escravos, não surtiram efeitos, precisavam de pessoas que criassem vínculos com o local para defendê-las. Havia critérios para a vinda de imigrantes, estes deviam ser casais que se multiplicassem para promover o povoamento local e defender o exército.

Com todas as questões e interesses apresentados por ambas as partes, houve um trabalho de divulgação persistente do Major Jorge Von Schaeffer ${ }^{3}$, que foi enviado por Dom Pedro I para fazer propaganda do Brasil na Alemanha. No princípio, o foco eram os militares para reforçar as fronteiras, colonos para trabalhar nos campos com mão de obra familiar, gerando economia para aquele local até então isolados. O major recebia pago por pessoa enviada, dessa forma obtinha lucros, beneficiando o Brasil com a ocupação, e a Alemanha com a redução do excesso populacional. Com a promessa tentadora de iniciar uma nova vida no Brasil, as famílias mais pobres decidiram deixar o seu país e emigrar. Os preparativos iniciavam com a venda de pertences, o que envolvia inclusive as terras.

Difícil era a despedida dos parentes, cujos rostos nunca mais veriam. Ouviu-se muito choro e comoventes canções de despedida. Os emigrantes partiam na carroça do vizinho ou de trem até o porto de Hamburgo. Aí, precisavam aguardar a chegada do navio que os levariam para o outro lado do oceano Atlântico, para a América, para o desconhecido Brasil. Durante a espera, que podia durar semanas ou meses, os alemães gastavam suas poucas economias em alimentação (ROCKENBACH e FLORES, 2004, p. 11-12).

Ao chegar ao porto ficavam em quarentena e recebiam o certificado de cidadania brasileira, pois caso houvesse arrependimentos, não poderiam voltar para a Alemanha. Partiam de Hamburgo, seguiam em navios transatlânticos, percorrendo 12.000 quilômetros, durante três meses de viagem. Devido à vulnerabilidade sanitária nos porões dos navios, vários imigrantes adoeciam, chegando à morte, onde os corpos eram enrolados em lençóis e jogados ao mar. Os sobreviventes chegavam ao Rio de Janeiro e aguardavam por algum tempo na cidade, o que implicava em meses de espera até a chegada das pequenas embarcações com rumo a Porto Alegre (BRAUN, 2017).

Rockenbach e Flores (2004), relatam que em 17 de julho de 1824 chegaram os primeiros 39 imigrantes em Porto Alegre, após seguiram em barcos pelo Rio dos Sinos, chegando em Real

\footnotetext{
${ }^{3}$ Ver Jean Roche. A colonização alemã e o Rio Grande do Sul. Porto Alegre: Globo, 1969. Vol.I. Ver ainda SCHRÖDER, Ferdinand. A emigração alemã para o Sul do Brasil. Porto Alegre EdiPUCRS; São Leopoldo: Unisinos, 2003. (Tradução de Martin Dreher).
} 
Feitoria do Linho-Cânhamo (atualmente São Leopoldo) no dia 25 de julho, onde havia um casarão governamental para armazenamento de insumos e linho-cânhamo, que era uma planta pequena fibrosa, utilizada para a confecção de cordas. No local ficaram alojados por meio ano, aguardando a demarcação das terras. Entre 1824 e 1830, foram enviados por Schaeffer 5.350 imigrantes para São Leopoldo. Segundo Muller (2004):

\begin{abstract}
É fácil imaginar a viagem Sinos acima. Uma vegetação luxuriante, com árvores enormes e flores em profusão; muitos animais povoando as margens: jacarés, capivaras, ratões do banhado, fuinhas e, sem dúvida, uma cobra deitada preguiçosamente sobre um tronco caído, ao vivo e em cores: garças, biguás, um mundo de pássaros coloridos. Numa palavra: um encanto! Um mundo novo à espera de quem fizera uma viagem de 12.000 quilômetros em busca de uma nova Pátria. Do rio, carretas de boi levaram os imigrantes até a Feitoria. Era o dia 25 de julho de 1824, um domingo, data da fundação do primeiro núcleo de colonização alemã no sul do Brasil, que viria a transformar-se na cidade de São Leopoldo. Reconhecida por todas as cidades de origem alemã no Estado, a data é festejada em todos os quadrantes. (CAPEF, 20114).
\end{abstract}

Entre 1830 até 1846 , houve um período sem a vinda de imigrantes. Um dos motivos foi que o governo suprimiu todos os créditos para a vinda de estrangeiros, também em virtude dos dez anos da Revolução Farroupilha, que trouxeram grandes dificuldades e instabilidades para o Rio Grande do Sul entre os anos de 1835-1845. Iniciando a retomada em 45, sendo fundadas novas colônias (TUBINO, 2007).

Três leis auxiliaram para a retomada da imigração alemã. A Lei no 514, de 28 de outubro de 1848 , que concedeu a cada uma das Províncias "seis léguas em quadra de terras devolutas" destinadas exclusivamente à colonização. Lei Geral de Terras, no 601, de 18 de setembro de 1850, mudando a forma de acesso às terras no Brasil, sendo possível adquirir terras brasileiras somente através da compra, assim os imigrantes com poucos recursos acabavam trabalhando em fazendas, surgindo assim pequenas propriedades rurais no interior do estado.

A Lei Provincial no 304, de 1854, que regulamentou a Lei de Terras no Rio Grande do Sul, estabeleceu condições que nortearam o processo de colonização. Até então os imigrantes recebiam as terras gratuitamente. Após a lei, foram instituídas regras legais. Eram demarcadas as terras e realizadas as medições, divisão e a demarcação dos lotes que seriam colocados à venda com preço mínimo, ficando reservadas áreas para estradas, portos, igrejas, cemitérios e outras necessidades públicas. O pagamento teria que ser realizado em um período de cinco anos, ultrapassando este prazo pagariam uma taxa de $1 \%$ ao mês. As terras ficavam hipotecadas até o

\footnotetext{
${ }^{4}$ O conteúdo apresentado por CAPEF (2011), é baseado em MÜLLER, Telmo L. 1824: Antes e Depois. A imigração alemã no Rio Grande do Sul, Porto Alegre, 2004.
} 
débito, sendo proibida a utilização da mão de obra escrava nas propriedades ${ }^{5}$ (ROCHE, 1969).

Em 7 de setembro de 1858, foi fundada a Colônia Provincial de Nova Petrópolis. A área escolhida para a fundação da nova colônia ultrapassa as divisas de São Leopoldo, mas não deixava de ser uma continuidade rumo ao norte da Capital da Província, povoando a região situada entre os rios Cadeias e Caí (PAZ, 2006). Coube ao Agrimensor Argentino José Maria Vidal explorar, realizar as medições das terras da colônia e verificar se possuía boas condições para a agricultura, facilidades para o escoamento da produção local e comunicação entre as colônias. Segundo Relatório de Vidal, "em virtude disto, criei aí uma colônia, e andei medir nesse lugar prazos coloniais e pela sua posição e configuração de seu terreno a denominei "Nova Petrópolis'". (PICCOLO, 1989, p. 50).

A Colônia Provincial de Nova Petrópolis foi planejada e dividida em lotes, com aproximadamente 50 hectares cada, organizadas em Linhas e Picadas, o que proporcionou espaços com qualidade do solo e água, divididos a cada 10 quilômetros (Figura 1).

Figura 1 - Mapa de Nova Petrópolis em 1870.

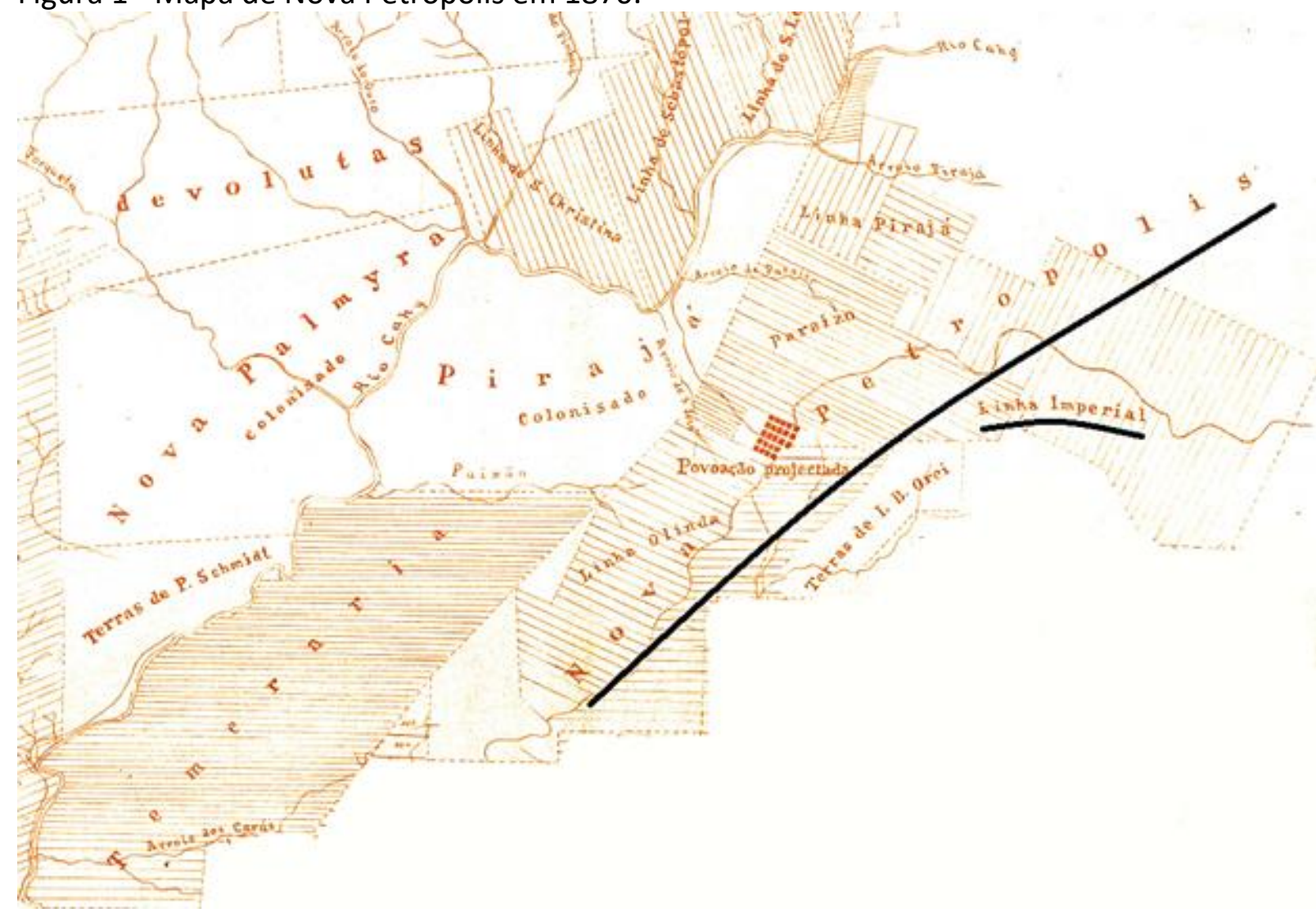

Fonte: Heuser (s./d. $)^{6}$.

\footnotetext{
${ }^{5}$ Ver Jean Roche, capítulo referente à Legislação na Primeira fase de colonização alemã.

${ }^{6}$ O conteúdo apresentado por Heuser (s./d.), representa: Mapa original de Ernst Müzell e Adalbert Jahn (1870). Copiado pelo Eng. Pedro Pereira Cotta (1970). Escaneado por Gaspar Henrique Stemmer. Fonte: https://heuser.pro.br/showmedia.php?medialD=749.
} 
Com o passar do tempo, surgiram pequenos vilarejos que serviram para abastecer a Sede Colonial, denominada de "Stadplatz", atualmente Centro do município. O nome de "Nova Petrópolis" é uma homenagem ao Imperador D. Pedro II, governante que tinha grande popularidade na época e o nome se deve graças às semelhanças com a cidade serrana de Petrópolis no Rio de Janeiro, local que a família real visitava com frequência (DEPPE, 1988).

O Cadastro da Colônia com a chegada dos imigrantes em linhas segundo ordem cronológica são as seguintes: Linha Imperial e Linha Olinda em 1845, Sebastopol em 1846, Linha Pirajá de 1860 a 1865, 13 Colônias em 1866, Riachuelo em 1869, Linha Brasil em 1874, Linha Araripe em 1874 e Linha Gonçalves Dias em 1877. Recebendo imigrantes da Renânia, Pomerânia, Saxônia, Baviera, Prússia e Boêmia. (PICCOLO, 1989). Segundo Roche (1969, p.109-110), a criação da colônia Nova Petrópolis tinha como objetivo "balizar a estrada entre Porto Alegre e a borda superior do Planalto; mas como essa rodovia foi inaugurada somente em 1944, a colônia não conheceu senão uma atividade reduzida".

A Colônia Provincial de Nova Petrópolis tornou-se distrito de São Sebastião do Caí de 1875 até 1955. Foi um período de dificuldades, devido à ausência de representantes administrativos, falta de recursos e a distância com o distrito. Foram anos de descontentamento e fortes atritos políticos, mas em 24 de setembro de 1953, através da Lei Estadual no. 2.116, que estabelecia normas para a criação de novos municípios no Rio Grande do Sul, a população do distrito se organizou para participar de um plebiscito que era exigência necessária para formalizar o ato. Em 20 de dezembro de 1953, ocorreu o plebiscito que legitima a emancipação política de Nova Petrópolis. Participaram da votação 1.771 eleitores habilitados.

Quadro 1 - Resultado do plebiscito quanto a emancipação de Nova Petrópolis.

\begin{tabular}{|l|c|c|}
\hline LOCALIDADES & PRÓ-EMANCIPAÇÃO & CONTRA EMANCIPAÇÃO \\
\hline Nova Petrópolis (sede) & 380 & 00 \\
\hline Linha Brasil & 34 & 47 \\
\hline Linha Araripe & 61 & 23 \\
\hline Nove Colônias & 95 & 11 \\
\hline Linha Olinda & 127 & 04 \\
\hline Linha Imperial & 223 & 17 \\
\hline Picada Café & 93 & 16 \\
\hline Nova Palmira (parte) & 124 & 08 \\
\hline Joaneta (São Leopoldo) & 227 & 207 \\
\hline Ivoti & 05 & 65 \\
\hline Totais & 1.379 & 392 \\
\hline
\end{tabular}

Fonte: $\mathrm{Paz}(2006)$.

Após a votação favorável e os esforços da comunidade, em 15 de dezembro de 1954 houve a criação do município, pela Lei no. 2.518, cuja instalação ocorreu em 28 de fevereiro de 
1955 (PAZ, 2006). Com a criação do município, os habitantes estavam unidos pela língua materna, pois no Rio Grande do Sul estavam distantes dos centros urbanos e alocados em pequenas localidades, sendo assim, mantiveram a sua língua devido ao pouco contato com os gaúchos. A língua era um meio de demonstrar afetuosidade a pátria mãe, e muitos mantiveram diversos elementos identitários de seu lugar de origem. O isolamento da colônia até então favoreceu a formação de uma homogeneidade cultural de origem europeia, carregando elementos da cultura de partida, mantendo e adequando a nova sociedade esses padrões. Muitos desses costumes que se mantiveram em algumas comunidades foram transportados pela cultura da imigração e cultivados em suas localidades.

\section{Capital Nacional do Cooperativismo}

Nova Petrópolis foi o berço do Cooperativismo de Crédito Rural, especialmente por sediar a primeira cooperativa de Crédito da América Latina em atividade desde 28 de dezembro de 1902. Esse fato refere-se a Caixa de Economias e Empréstimos Amstad, que teve como líder o Padre Theodor Amstad, pioneiro do cooperativismo no Brasil (Figuras 1 e 2). Naquela época não existiam bancos, desta forma todos os moradores necessitavam se deslocar até São Sebastião do Caí para ter acesso ao serviço (PAZ, 2006). Através da Lei Federal 12.205/2010, Nova Petrópolis conquistou o título de Capital Nacional do Cooperativismo, em virtude do seu valor histórico e por ainda possuir nove cooperativas em atividades, sendo que cinco delas são de origem local, reafirmando o título recebido (NOVA PETRÓPOLIS, 2020).

O título obtido pelo município concentra-se na figura do Padre Theodor Amstad que foi o grande idealizador da instituição de crédito em Nova Petrópolis. O padre também ficou conhecido por percorrer milhares de quilômetros montado em uma mula, levando conhecimento e apoio às comunidades do interior do Rio Grande do Sul. A sua história é preservada na comunidade Linha Imperial em Nova Petrópolis (SCHIAVO, 2019).

Marra (s./d, p. 36) apresenta um breve histórico do Padre Amstad onde destaca seu papel de integrador dos colonos e como colaborador de iniciativas em prol da comunidade.

O padre Theodor Amstad, conhecido como o "Pai dos Colonos", nasceu em Beckenried, à beira do Lago dos Quatro Cantões, na Suíça, em 9 de novembro de 1851. Era filho de um comerciante e descendente direto, em 13o grau, de São Nicolau de Fue, padroeiro da Suíça. Lá ele estudou, e ordenou-se padre jesuíta em 8 de setembro de 1883, na Inglaterra. Em 1885, veio ao Brasil e trabalhou nas colônias de descendência alemã do Rio Grande do Sul. (MARRA, s/d, p.36). 
Ao chegar ao Brasil, o padre tinha como objetivo fundar uma instituição de crédito, se tratando de um planejamento, não sendo por acaso, "desde que cheguei ao Brasil, ocupava-me com o plano de neste belo e rico país, descobrir a modalidade de fundar uma verdadeira ação associativa, que fosse de utilidade comunitária" (AMSTAD, 1981, p. 196).

Figura 2 - Pe. Amstad

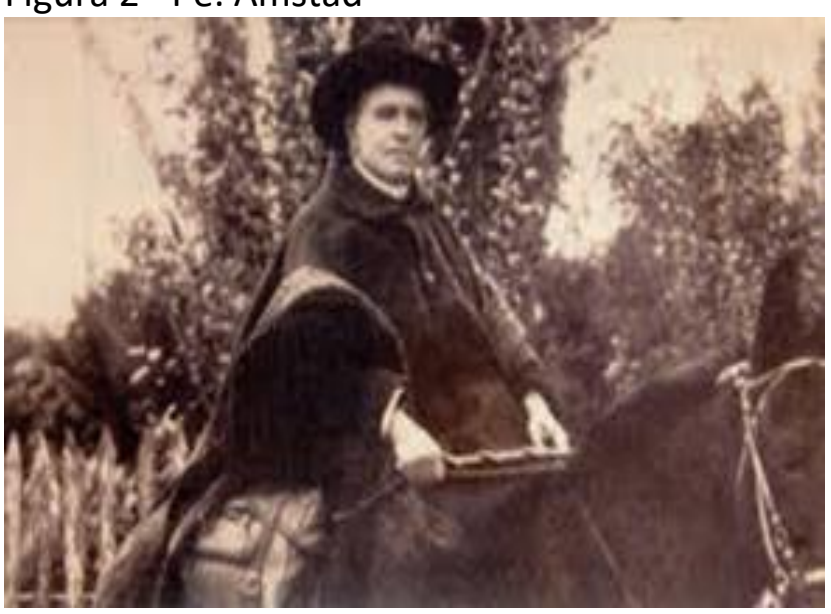

Fonte: Sicredi União RS (2019).
Figura 3 - Pe. Amstad na comunidade

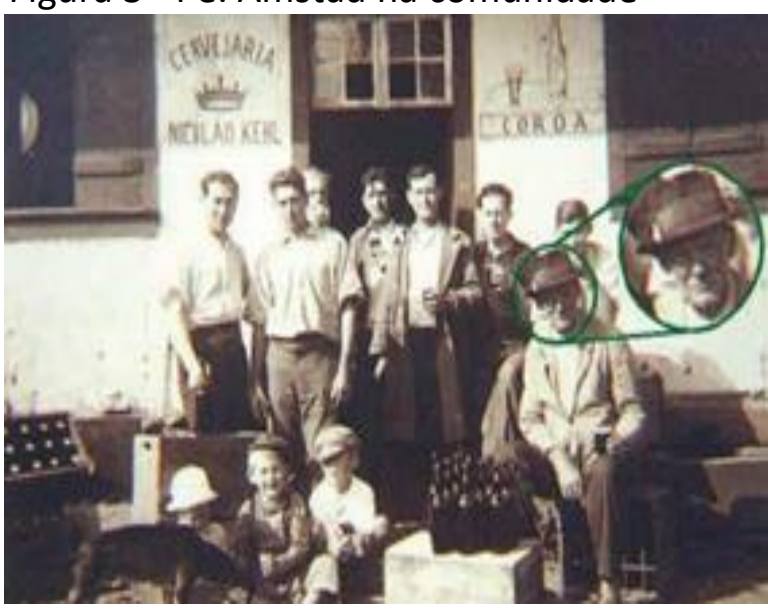

Fonte: Arquivo Histórico Municipal (2020).

Conforme Kleemann (2013), durante 38 anos Amstad percorreu diversas regiões do Rio Grande do Sul, no lombo de uma mula, assim fundando 38 cooperativas, sindicatos, hospitais, asilos, escolas, meios de comunicação, igrejas e até mesmo novas colônias, como Cerro Largo e Santo Cristo. Amstad era organizado e possuía uma ficha catálogo com os moradores da região. Por meio destes dados, verificou que a sua comunidade religiosamente estava bem acolhida, porém não economicamente, então com seus conhecimentos iniciou o processo da constituição de uma cooperativa de crédito em Nova Petrópolis.

Os primeiros passos para a fundação da cooperativa ocorreu no dia 19 de outubro de 1902 em Nova Petrópolis, então 3o distrito do município de São Sebastião do Caí. A reunião marcada era para tratar dos assuntos do Sindicato Agrícola, porém se fizeram presentes, somente os moradores da localidade. O que era para ser uma assembleia geral se transformou em uma reunião, só do distrito de Nova Petrópolis, sendo abordados os temas locais. Amstad conduziu a reunião e mencionou as dificuldades financeiras na colônia, apresentando o projeto da cooperativa de crédito, trazendo o exemplo europeu aos presentes. O projeto teve adeptos, porém a maioria foi contra a proposta, mas Amstad não recuou. De forma estratégica, renovou os apelos e fez com que cada morador presente se manifestasse, assim por meio das informações e opiniões ditas, conseguiu mais adeptos para a criação, através da insistência, alcançando 15 adeptos. Na oportunidade, o Sr. Anton Maria Feix foi designado a elaborar uma minuta de 
Estatuto Social, que seria debatido em nova reunião no dia 09 de novembro de 1902 (SICREDI PIONEIRA RS, s./d.).

Muitos interessados se fizeram presente no dia proposto, onde é iniciada a leitura do estatuto proposto por Feix, mas é preciso que a reunião seja interrompida, devido forte temporal que atinge Nova Petrópolis, onde todos deixam o local às pressas para se protegerem. Por consequência dos fortes ventos o prédio da reunião desmorona e na região inúmeros prejuízos são registrados. Nova reunião é marcada para 23 de novembro de 1902 e por sua vez também foi adiada pela morte da esposa do Dr. Johann Müller Von Milasch, entusiasta do projeto. Aparentando que tudo conspirava contra as ideias de Amstad, em nova reunião em 28 de dezembro de 1902, no salão de baile Kehl, em Linha Imperial, longe 8km do centro de Nova Petrópolis, aprovaram os estatutos e foi fundada a Caixa Econômica de Empréstimos Amstad. A Caixa Econômica de Empréstimos Amstad deu origem portanto a Cooperativa, denominada Sicredi Pioneira RS, uma das 10 maiores cooperativas financeiras do Brasil. A assinatura da ata contou com a presença de 20 pessoas que assumiram o compromisso da sua criação, liderados pelo Padre Amstad (Figura 3). Da ata de fundação, redigida em língua alemã pelo próprio Padre Amstad, temos a seguinte tradução:

\footnotetext{
Ata de fundação da Sociedade Cooperativa Caixa de Economia e Empréstimos de Nova Petrópolis, realizada na casa do Sr. Nicolau Kehl, dia 28 de dezembro de 1902, em Linha Imperial. Os 19 sócios abaixo assinados, fundaram definitivamente a Caixa de Economia e Empréstimos Amstad e aprovaram os estatutos apresentados com pequenas alterações. Pela elaboração abnegada e bem feita dos estatutos pelo Sr. Anton Maria Feix a assembleia agradeceu calorosamente. Logo após o registro a Caixa deverá começar a funcionar. As cotas de capital de giro deverão ser pagar até o dia 15 de janeiro do próximo ano. Como tesoureiro provisório foi escolhido o Sr. Josef Neumann Senior e encarregado de tomar as devidas providências. Nome dos sócios fundadores presentes: Alfred Steglich, August Stahl, Hermann Kaiser, Jacob Krug, Franz Raimann, Nicolaus Stahl, Anton Maria Feix, Josef Oppitz, Nicolaus Kehl, Josef Hillebrand, Franz Hillebrand, Anton John, Carl Bratz, Josef Neumann Filho, Johann Brunner, Franz Opppitz, Albert Drechsler, Friederich Stoffels e Johann Grings (COOPERATIVISMO DE CRÉDITO, s./d.).
}

Entre 1903 até 1933 a sede da instituição funcionou na casa (Figura 4) em estilo 'enxaimel', datada de 1900 de Joseph Neumann Senior que foi o primeiro gerente da Caixa Econômica de Empréstimo Amstad (CAPITAL DO COOPERATIVISMO, s./d.). 
Figura 4. Primeira Sede (1903-1933).

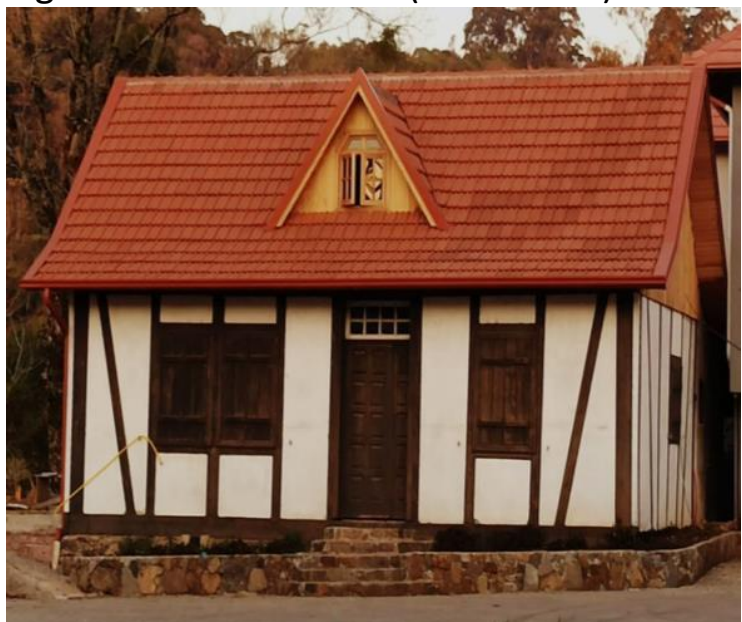

Fonte: Acervo de Rodrigo dos Santos (2020).
Figura 5. Segunda Sede.

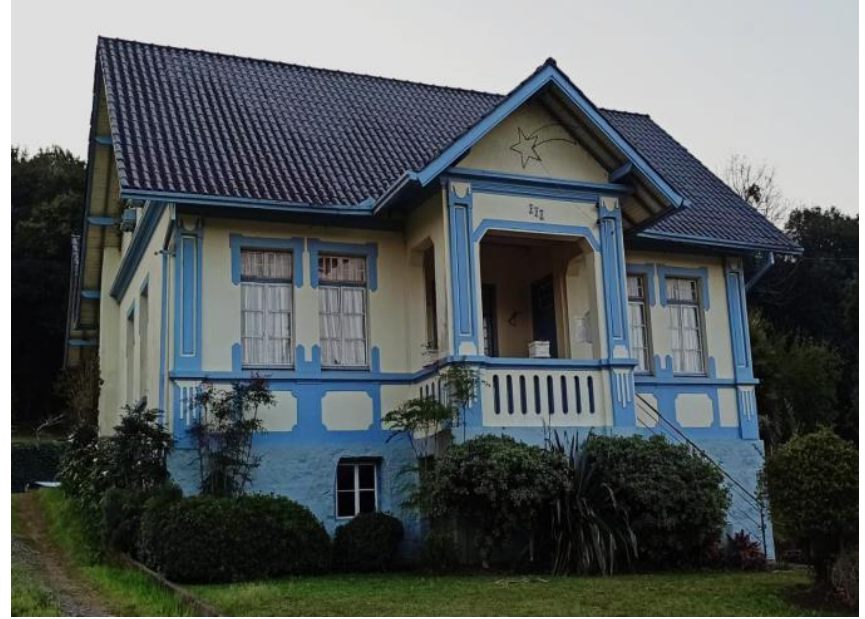

Fonte: Acervo de Rodrigo dos Santos (2020).

Em 1933, a Cooperativa foi transferida para a casa do então gerente José Otto Neumann na vila de Linha Imperial (Figura 5). Em 1952 com a presença do Governador do Estado, General Ernesto Dornelles, foi colocada a pedra angular do prédio (Figura 6), em evento solene contando com mais de 1.500 pessoas no ato, onde também foi comemorado os 50 anos de fundação. No ano de 1953, a sede foi transferida para o primeiro prédio novo, localizado ao lado da Praça Padre Amstad (Figura 7). Em 1958 é criada a filial, no centro de Nova Petrópolis.

Figura 6. Lançamento da pedra da sede.

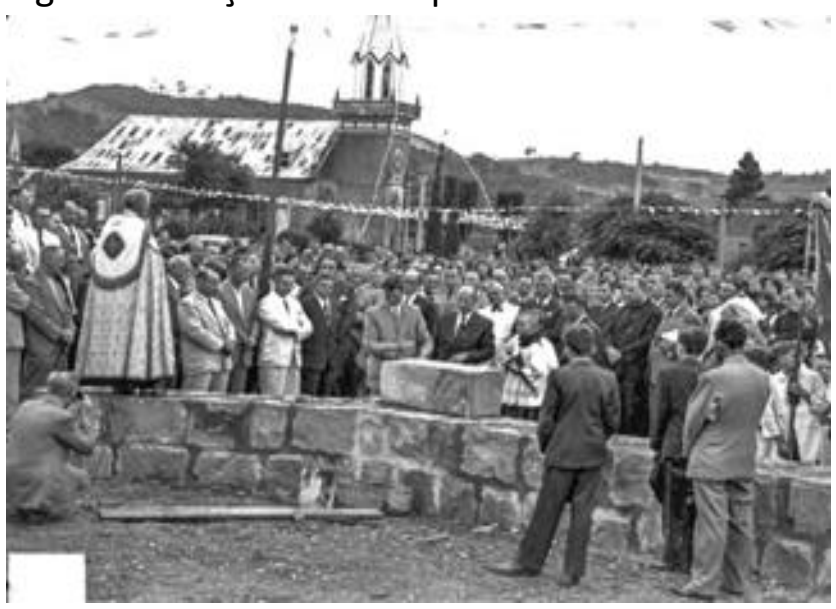

Fonte: Acervo Célia Weber Heylmann.
Figura 7. Sede própria.

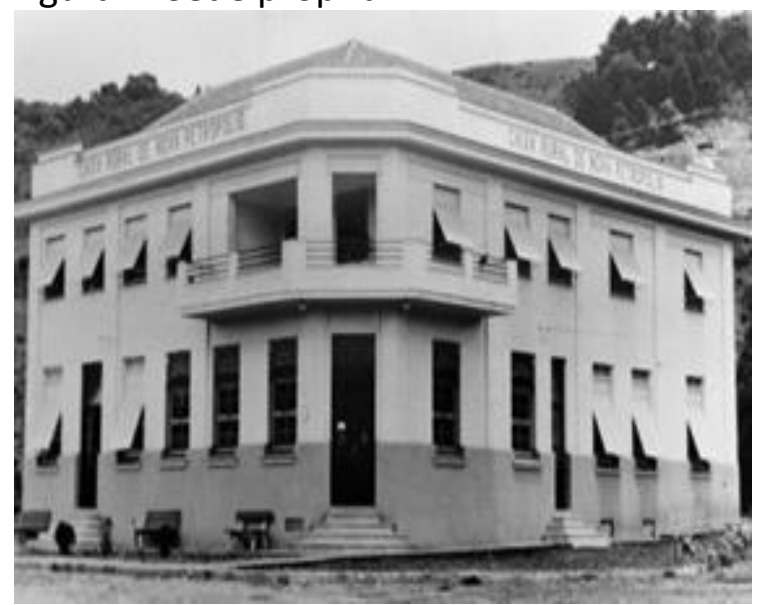

Fonte: Acervo Célia Weber Heylmann.

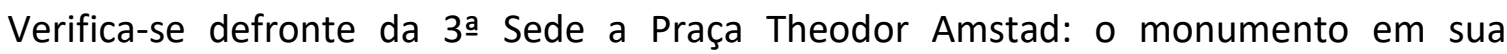
homenagem, inaugurado em 1942. Nesta praça ainda se encontra o Monumento À Irmandade, representando a integração com os municípios de Jablonec nad Nisou, na República Tcheca e Sunchales, na Argentina, esta que é a Capital do Cooperativismo na Argentina. 


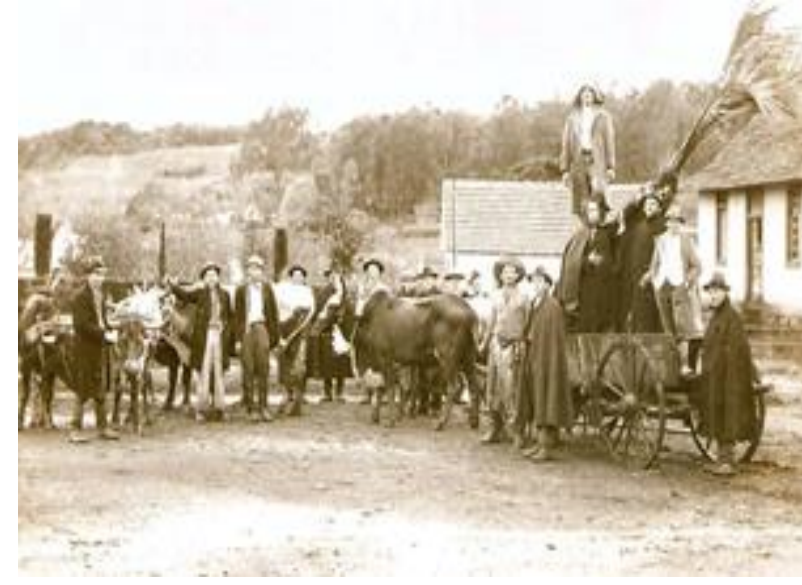

Fonte: Acervo Célia Weber Heylmann.

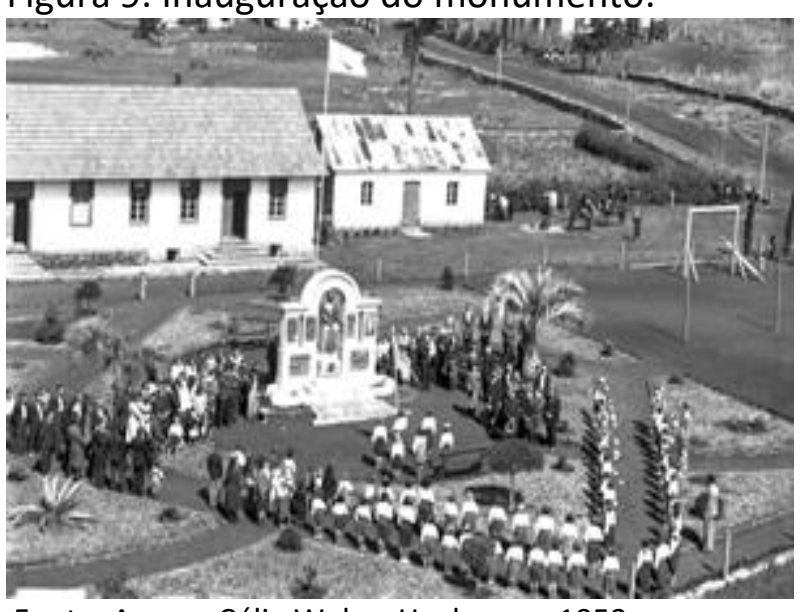

Fonte: Acervo Célia Weber Heylmann, 1953.

\section{Possibilidades de Turismo em Nova Petrópolis}

O município de Nova Petrópolis está em pleno desenvolvimento turístico, no qual vem planejando e se estruturando para receber os turistas e se consolidar, junto aos demais municípios da região. Possui diversos roteiros, atrativos naturais e culturais, eventos, artesanato, gastronomia farta, diversas opções de hospedagem, natureza, paisagem e um povo hospitaleiro. E isso tem sido um grande fator para o desenvolvimento local, social, econômico. Com isto, temse no turismo um vasto campo de atuação, podendo atuar com um olhar dirigido ao desenvolvimento sustentável do município e muitas atrações culturais para estimular a vinda de turistas.

O município possui diversas atrações turísticas como a Torre Medieval na entrada da cidade, a Sede da Rota Romântica, importante entidade que abrange 14 municípios, ligando a planície do Vale dos Sinos e o Planalto da Serra Gaúcha. O trajeto sinuoso, por diversas vezes esteve listado entre as mais belas e charmosas estradas do Brasil. Reconhecimento alcançado pelo cuidado e pela marca do roteiro, as árvores de Plátanos, onde tem na sua folha o símbolo da associação (ROTA ROMÂNTICA, 2020).

Com o surgimento do fluxo de turistas, houve a implantação dos primeiros equipamentos turísticos, que deram ênfase para a estrutura gastronômica do município, com capacidade de receber simultaneamente mais de 4 mil pessoas, distribuídas em mais de 50 estabelecimentos, onde se destaca o tradicional café colonial, surgido na década de 1950. A cidade oferece uma ampla culinária, como: cozinha típica alemã e italiana, sopas, galeterias, pizzarias, padarias, confeitarias e cervejarias que ganharam força na última década. No segmento hoteleiro possui 
mais de 32 empreendimentos, hospedando mais de 1.800 pessoas simultaneamente em hotéis, pousadas, resorts e albergues (NOVA PETRÓPOLIS, 2020).

Possui um vasto calendário de eventos, organizado pela prefeitura municipal, associações, comunidade e iniciativa privada, sendo o seu grande meio de divulgação e de investimentos. Dentro de um cronograma anual, abrindo o calendário municipal com atividades de lazer, esportivas, de bem-estar e ao ar livre, temos o Verão no Jardim da Serra Gaúcha. No mesmo período, ocorre a tradicional Festa do Figo, com 45 anos de história, realizado intercaladamente nas localidades de Linha Brasil e Linha Araripe. Em maio um dos maiores eventos, o Festimalha atrai consumidores de todo Brasil, para conhecer as novas coleções das tendências para o inverno, que são lançadas no Centro de Evento da cidade. Com cunho cultural, o Festival Internacional do Folclore é realizado desde 1973, sendo considerado um dos maiores do Brasil. Recebe mais 70 grupos e 1.500 dançarinos, vindos de todos os continentes. O evento ocorre por duas semanas na Rua Coberta e tem parceria com a Organização Internacional de Folclore, associada a ONU (Organização das Nações Unidas). Nova Petrópolis promove também eventos em épocas festivas, como a Magia da Páscoa, juntamente com a Chocofest e o Natal no Jardim da Serra Gaúcha. Bianualmente recebe o Rural Show, maior evento da agricultura familiar do Brasil (ACINP, 2018).

São inúmeros os atrativos e roteiros disponíveis para visitar no município, tendo como destaque o Parque Aldeia do Imigrante, inaugurado em 1985 em celebração aos 150 anos da imigração alemã no Rio Grande do Sul, possui prédios centenários, que foram desmontados no interior do município e remontados em forma de uma aldeia, contendo uma capela de 1875, além da primeira escola de Nova Petrópolis, a casa do professor, salão de baile, ferraria, cemitério, museu municipal e outros prédios que contam a história dos antepassados.

Seguindo na mesma temática o "Esculturas Parque Pedras do Silêncio" é o primeiro parque de iniciativa privada no município, inaugurado em 2014, tem como objetivo resgatar a história da imigração germânica e divulgá-la por intermédio de esculturas em pedras. São mais de 80 esculturas ultrapassando 300 toneladas. 0 nome surgiu por se entender que as esculturas (as pedras) estão em silêncio, contando a história da imigração germânica, principalmente dos que iniciaram a colonização de Nova Petrópolis. Saindo do segmento histórico/cultural, no centro da cidade a famosa e florida Praça das Flores e o Labirinto Verde que diverte os visitantes que buscam o centro, passando pelos ciprestes verdes em formato de círculos, sendo o ponto turístico mais visitado. Antigamente no local existia uma pequena quadra de esportiva, sendo substituída pelo labirinto em 1989. 
Por fim, outro ponto muito visitado é o "Ninho das Águias", à 8 km da cidade e com 684 metros de altitude, possui vista privilegiada e um lindo pôr do sol, sendo considerado um dos melhores locais de voo livre no Brasil. (TURISMO NOVA PETRÓPOLIS, s./d.).

Todo desenvolvimento turístico e histórico da cidade, oportunizou o recebimento de alguns títulos, como: Jardim da Serra Gaúcha pelos seus floridos jardins, Simplesmente Germânica, por meio da sua colonização de imigrantes alemães e Capital Nacional do Cooperativismo, com seu berço na comunidade de Linha Imperial no interior do município, estas duas últimas titulações iremos aprofundar os estudos históricos de cada uma.

\section{Considerações finais}

Nova Petrópolis com todo o seu potencial natural, cultural e histórico, seu posicionamento geográfico e sua infraestrutura urbana, reúne condições para o desenvolvimento do setor turístico. Desta forma, integra-se de forma competitiva aos destinos consolidados no Rio Grande do Sul, contribuindo para o desenvolvimento do setor no Estado e oportunizando a inclusão social e econômica de uma significativa parcela da população local.

Ao estudar a história da imigração alemã no Rio Grande do Sul, de forma detalhada no município de Nova Petrópolis, reconhece-se a força de sua germanidade e suas contribuições para o desenvolvimento local, regional. Vale ressaltar o pioneirismo no cooperativismo com o Padre Theodor Amstad com a Caixa de Economias e Empréstimos, tendo como sede e início das atividades em Linha Imperial no ano de 1902.

Ao pesquisar as origens migratórias do município de Nova Petrópolis fica nítido o forte enraizamento com a cultura alemã, no qual a história é preservada e divulgada por meio do turismo e suas manifestações culturais. No interior de Nova Petrópolis, como é o caso da Linha Imperial, apresenta um grande potencial turístico com a história do cooperativismo e da cultura lá existente, além de possuir outros atrativos e eventos. Utilizando o trânsito de turistas da região e por estar localizada entre Nova Petrópolis e Gramado, a comunidade de Linha Imperial poderá se desenvolver e fomentar o turismo cultural, através da história e fatos relevantes, mas principalmente pelos atrativos e estrutura turística existente.

Contribuindo para a temática Herédia e Tronca (2016, p. 355), apontam no turismo cultural um meio de preservação, pois trata-se de uma comunidade que é consciente dos seus valores históricos, ainda abriga famílias que tiveram seus familiares envolvidos na construção da própria comunidade e de todo o seu entorno. Os valores existentes fundamentam a necessidade 
da preservação e vislumbram uma possibilidade de abertura, junto ao turismo cultural, assim garantindo a manutenção da sua própria história. Por sua vez, as autoras apresentam no turismo a oportunidade de preservação e divulgação do seu patrimônio. As autoras afirmam: "A única forma de manter a memória desse patrimônio é garantir a sua preservação por meio legal cuja ação pode ser eficaz no sentido de assegurar sua proteção, ou através de sua disponibilização turísticas, como mostram experiências europeias".

O turismo cultural abrange as atividades de vivência do turista, juntamente com os elementos representativos da história, cultura e memória de uma comunidade. No caso da comunidade de Linha Imperial que possui muitos bens culturais, é possível garantir a preservação e divulgação de seu patrimônio por meio da história do cooperativismo, dos acontecimentos relevantes a localidade, aos prédios históricos, aos monumentos, por meio do reconhecimento de seus bens.

As potencialidades turísticas podem ser fomentadas por meio de investimentos públicos e privados, e contribuir para fortalecer a preservação e a valorização do município. Os aspectos históricos e culturais, aqui relatados representam a oportunidade da estruturação de um produto turístico. Consequentemente, poderá aumentar o fluxo de visitantes, sendo o turismo um meio de desenvolvimento, através do turismo cultural, ocorrendo a valorização e promoção da cultura, preservação do patrimônio histórico e cultural, com a geração de oportunidades de negócios e empregos, respeitando valores, símbolos e significados presentes na cultura do município de Nova Petrópolis.

\section{Referências}

ACINP. Departamento de Turismo. Como chegar, s./d. Disponível em: <http://www.turismonovapetropolis.com.br/localizacao.php>. Acessado em 13 mai. 2020.

Perfil Socioeconômico 2017/2018 de Nova Petrópolis | RS, 2018. Disponível em: <http://acinp.com.br/arquivos/Perfil_Socioeconomico_NP_2017-2018.pdf. Acessado em 12 mai. 2020.

AMSTAD, Teodoro. Memórias autobiográficas. Trad. de Arthur Rabuske. São Leopoldo: Unisinos, 1981.

AREND. Isabel Cristina e WITT, Marcos Antônio. História, cultura e memória: 180 anos da imigração alemã. São Leopoldo, RS: Oikos, 2005.

BRASIL. Ministério do Turismo. Mapa do Turismo: 2019-2021, 2020. Disponível em: <http://www.mapa.turismo.gov.br/mapa/init.html\#/home>. Acessado em 03 ago. 2020. . Ministério do Turismo. Turismo Cultural: orientações básicas. / Ministério do Turismo, Secretaria Nacional de Políticas de Turismo, Departamento de Estruturação, Articulação e 
Ordenamento Turístico, Coordenação-Geral de Segmentação. - 3. ed.- Brasília: Ministério do Turismo, 2010. Disponível em:

<http://www.turismo.gov.br/sites/default/turismo/o_ministerio/publicacoes/downloads_publi cacoes/Turismo_Cultural_Versxo_Final_IMPRESSxO_.pdf>. Acessado em 19 mai. 2020.

BRAUM, Felipe Kuhn. Alemães no Brasil: 1824 - 1945. São Leopoldo, RS: Oikos, 2017.

CAPEF. 1824: Imigração alemã, 2011. Disponível em:

<http://www.genealogiacapef.com.br/index.php/de/fatos-historicos/133-imigracao-alema>. Acessado em 13 mai. 2020.

CAPITAL DO COOPERATIVISMO. O roteiro do cooperativismo. Disponível em: < http://www.capitaldocooperativismo.com.br/cooperativismo/roteiro.asp>. Acessado em 31 jun. 2020.

COOPERATIVISMO DE CRÉDITO. Sicredi Pioneira RS - a pioneira na América Latina. Disponível em:<https://cooperativismodecredito.coop.br/cooperativismo/historia-docooperativismo/sicredi-pioneira-rs-a-pioneira-na-america-latina/>. Acessado em 29 ago. 2019.

DEPPE, Gessy (org,). Contribuição para a história de Nova Petrópolis: Depoimentos. Caxias do Sul, RS: EDUCS, 1988.

HERÉDIA, Vania Beatriz Merlotti e TRONCA, Bruna. Patrimônio Industrial e Turismo: A Vila Operária de Galópolis, Caxias do Sul, RS. Caxias do Sul: Revista Rosa dos Ventos - Turismo e Hospitalidade, 8(III), pp. 343-357, jul-set, 2016. Disponível em:

<file:///C:/Users/rodri/Downloads/4404-17458-1-PB.pdf>. Acessado em 19 mai. 2020.

HEYLMANN, Paulo Antônio. Entrevista: Praça Theodor Amstad, Linha Imperial. Entrevistador: Santos, Rodrigo José. Mestrando do Programa de Pós-Graduação em Turismo e Hospitalidades Mestrado, Universidade de Caxias do Sul. Nova Petrópolis: 2019. 1 arquivo .mp3 (11:48 min.). Entrevista concedida a pesquisa de Mestrado.

KLEEMANN, Flávio Luis. Cooperativismo Rural em Nova Petrópolis: Um estudo a partir da visão do associado de uma cooperativa local, 2013. Disponível em:

<https://www.lume.ufrgs.br/bitstream/handle/10183/87398/000908168.pdf?sequence=1>. Acessado em jun. 2020.

MARRA, Adriana Ventola. História do Cooperativismo: Aula 2. Disponível em:

$<$ http://proedu.rnp.br/bitstream/handle/123456789/578/Aula_02.pdf?sequence=7\&isAllowed =y>. Acessado em 21 jun. 2020.

NOVA PETRÓPOLIS. Capital Nacional do Cooperativismo, 2020. Disponível em: https://www.novapetropolis.rs.gov.br/pagina/capital-nacional-do-cooperativismo. Acessado em 21 mai. 2020.

Secretaria de Turismo, Indústria e Comércio. Turismo, 2020. Disponível em:

<https://www.novapetropolis.rs.gov.br/secretarias/turismo-industria-e-comercio >. Acessado em 12 mai. 2020.

PAZ, Ivoni Nör. (org,). Evolução Política e Econômica de Nova Petrópolis: de colônia provincial a município, da pequena propriedade ao Turismo. Porto Alegre, RS: Corag, 2006.

PICCOLO, Helga Iracema Landgraf. Contribuição para a história de Nova Petrópolis: Colonização e Evolução da Colônia. Caxias do Sul, RS: EDUCS, 1989.

ROCHE, Jean. A colonização alemã e o Rio Grande do Sul. Porto Alegre, RS: Editora Globo, 1969. 
ROCKENBACH, Silvio Aloysio e FLORES, Hilda Agnes Hübner. Imigração alemã: 180 anos história e cultura. Porto Alegre, RS: Corag, 2004.

ROTA ROMÂNTICA. Mapa da Rota. Disponível em: <https://

https://www.rotaromantica.com.br/pt/mapa>. Acessado em 12 mai. 2020.

SCHIAVO, Talita. Padre Theodor Amstad, pioneiro do cooperativismo de crédito brasileiro. Disponível em: <https://www.diocesesaojoao.org.br/2019/03/19/padre-theodor-amstadpioneiro-do-cooperativismo-de-creditobrasileiro/>. Acessado em 20 ago. 2020.

SICREDI PIONEIRA RS. Vídeo dos $\mathbf{1 0 0}$ anos da Sicredi Pioneira RS. Disponível em: < https://www.youtube.com/watch?v=CujTjb_KqJA>. Acessado em 31 jun. 2020.

SICREDI UNIÃO RS. Relatório Anual 2020. Disponível em: < https://sicrediuniaors.com.br/relatorio-anual-2019>. Acessado em 30 ago. 2020.

TUBINO, Nina. Das Deutschtum in Brasilien: A Germanidade no Brasil. Porto Alegre, RS: Sociedade Germânia, 2007.

TURISMO NOVA PETRÓPOLIS. Ninho das Águias. Disponível em: <https://turismo.novapetropolis.rs.gov.br/locais/ninho-das-aguias>. Acessado em 20 ago. 2020. 